Ethiopian Journal of Environmental Studies \& Management 7(2): 134 - 141, 2014.

ISSN:1998-0507

doi:http://dx.doi.org/10.4314/ejesm.v7i2.4

Submitted: October 19, 2013

Accepted: February 19, 2014

\title{
HAZARDOUS WASTE MANAGEMENT BY HEALTHCARE INSTITUTIONS, ADDIS ABABA: IMPLEMENTATION OF LAWS AND REGULATION
}

\author{
FIKIRTE DEMISSIE TULU \\ Department of Geography and Environmental Studies, Bahir Dar University, Ethiopia \\ Email fikirkiya@gmail.com
}

\begin{abstract}
A study regarding healthcare institution waste management and practical implementation of laws and regulation was conducted in selected hospitals of Addis Ababa during the period of 2012/13. The entire healthcare system generates non-hazardous and hazardous wastes during healthcare processes. Therefore, this study focuses on assessment of the hazardous waste management of healthcare institutions in Addis Ababa and implementation of laws and regulation. Interview, questionnaire, and observations were employed to collect primary data whereas secondary data were collected from statutory organizations. For the study four hospitals were randomly selected. To analyze the data percentage and narration were used. The finding of the study shows that except Zewditu hospital, the rest use proper management to the hazardous waste. Lack of awareness about health hazards of healthcare waste, inadequate training, absence of waste management and disposal systems, insufficient financial and human resources, low priority given to the topic and lack of aware about legislative act are the most common problems connected with healthcare waste management. Therefore, efforts have to be exerted on creating awareness about internationally ratified conventions, the existing related laws and the regulations of healthcare waste management that are produced in regional and national level.
\end{abstract}

Key words: Healthcare, Hazardous, Incinerator, Regulations, Awareness, Safety Box

\section{Introduction}

Healthcare institutions provide medical care services that comprise diagnostic, therapeutic, research and rehabilitative services in an attempt to manage health problems and protect the public from different health risks. They are one of the complex institutions, which are frequently visited by people from every walk of life in the society without any distinction between age, sex, race and religion. All of them produce waste. Waste not properly managed, poses a threat to patients, public health, environment and personnel who handle these wastes (FMoH, 2012; Emmanuel, 2007). Handling, segregation, mutilation, disinfection, storage, transportation, and final disposal are vital steps for safe and scientific management of healthcare waste in any establishment (AAEPA, 2011).

The waste generated from the healthcare institutions is broadly categorized as nonhazardous waste and hazardous waste. This holds true only when segregation and separation of waste is practiced (Khajuria and Kumar, 2007; Umar and Yaro, 2009; Umar et al., 2009; Gabela, 2007). According to WHO (2004), around $85 \%$ of hospital wastes are non- hazardous and $15 \%$ are hazardous. Hazardous Waste is defined as "any unwanted material that is believed to be deleterious to human safety or health or the environment" (Federal Negarit Gazeta, 2002). Moreover, the hazardous waste includes infectious health-care waste, chemical, toxic or pharmaceutical waste, including cytotoxic drugs (antineoplastics), sharps (e.g. needles, scalpels), radioactive waste; and other hazardous waste (WHO, 2004).

The management of healthcare waste requires increased attention and diligence to avoid the substantial disease burden associated with poor practice, including exposure to infectious agents and toxic substances. Medical waste may contain highly toxic chemicals and can present a mechanism for transmission of diseases. The growth of the medical sector around the world over the last decade combined with an increase in the use of disposable medical products has contributed to the large amount of medical waste being generated (Patwary et al., 2009; Ogbonna et al., 2012).

According to WHO (2004), $15 \%$ to $25 \%$ of the healthcare institution is hazardous waste. The Federal Ministry of Health, Hygiene and Environmental Health Department have 
prepared Healthcare Waste Management National Guidelines (FMoH, 2008). Under this guideline, the hazardous waste of healthcare institution has been listed and the management way is also recommended. It is reported that health care institutions dispose of all wastes to municipal dumpsites without pre-treatment, leading to an unhealthy and hazardous environment around the health institutions, affecting patients, staff and the community (Ogbonna et al., 2012). Improperly disposed hazardous HCW (like syringes and needles in the absence of sterilization) can cause infectious of Hepatitis B, C and HIV (WHO, 2004) and poses indirect risks to humans through direct environmental effects by contaminating soil and ground-water (Abah and Ohimain, 2011). Study conducted by Muluken and Abera (2010) indicated as waste segregation and treatment are the most important interventions in the management of hazardous wastes but it was poorly practiced and medical waste is handled like any other municipal waste in many urban settings of Ethiopia. In Ethiopia, less attention is paid to the hazardous waste generated by healthcare facility because unlike the solid waste management hazardous waste does not have a separate proclamation in order to reduce the health and environmental risk. However, Ethiopia uses ratified international convention; it is not implemented since it does not have directives. Therefore, this study answers questions like how do healthcare institutions in Addis Ababa manage the hazardous waste produced due to process of healthcare? and What looks like practical implementation of laws and regulation on managing hazardous waste in Addis Ababa?

\section{Methodology}

This study is conducted in Addis Ababa, which is the Capital City of the Federal Democratic Republic of Ethiopia and diplomatic capital of Africa, the seat of numerous international and regional organizations. In the City there are 48 Hospitals, 78 health centers and 647 clinics (Addis Ababa Health Bureau, 2012). Of the hospitals six of them are specialized and they are under the governance of Federal Ministry of health $(\mathrm{FMoH})$.

Both primary and secondary data were collected from different institutions. Primary data were collected from hospitals, Addis Ababa Health Bureau and Food, Medicine and Health Care Administration and Control Authority (FMHACA). For the study four hospitals were randomly selected. These are Black Lion, All African Leprosy, TB Rehabilitation and Training Centre (ALERT), Zewditu and Gandi Memorial Hospital. The first two hospitals are under FMoH and the rest are under the Addis Ababa Health Bureau respectively.

The source for secondary data was Healthcare Waste Management National Guidelines of FMoH, 2008, Proclamations, and other documents. To collect the data offices of FEPA, Addis Ababa Health Bureau, and FMoH were visited.

To collect primary data interview, questionnaire and observation were employed. Interview was done with the FMHACA official and Addis Ababa Health Bureau Environmental Health Officer. On the other hand, questionnaire was administered for four hospitals hygiene and environmental health officials and one questionnaire per hospitals was given and filled. Totally four questionnaires were filled by two Federal Referral hospitals and two Addis Ababa City hospitals. Observation was also made to check the implementation of Healthcare Waste Management National Guidelines of FMoH, 2008. To analyze the data collected percentage and narration were used.

\section{Results and Discussion}

\section{Hazardous Waste Management by Healthcare Institutions in Addis Ababa}

According to FMoH (2008), Healthcare waste is not only a technical issue but also a management issue, and its safe treatment/management should become an integral feature of healthcare services. For this study four hospitals were visited, namely; Black Lion, ALERT Centre, Zewditu and Gandi Memorial Hospitals. In each hospital there was a designated waste management department for handling all wastes that are generated during healthcare. This department is known as Hygiene and Environmental Health. The inspection of waste management is done by Addis Ababa Environmental Health department for the hospitals under the administration of Addis Ababa city government. Moreover, FMHACA does inspection for Specialized and Teaching Hospitals in Addis Ababa.

\section{Collection and Segregation Mechanisms}

According the National Healthcare Waste Management Guideline (FMoH, 2008), healthcare facilities should use three bin system to segregate waste at source. These are black color for non-risk waste and collected in bag or 
bin; yellow color for Infectious clinical waste (different type) and stored in bag or bin; and yellow /white color for sharp waste and stored in safety box.

Table 3Use of color coded bin/box to collect waste

\begin{tabular}{llll}
\hline No. & Bin/Box & Number & Percentage \\
\hline 1 & Black bin & 3 & 75 \\
2 & Yellow bin & 3 & 75 \\
3 & Yellow/white safety & 4 & 100 \\
& box & & \\
\hline
\end{tabular}

Using these coded bin HCW segregation should be made at the source by healthcare provider during HCFs and then by cleaners. Table1 shows all the sampled hospitals used yellow/white safety box for the sharp waste generated during healthcare process. However, $75 \%$ of the hospitals used the black and yellow bin for general waste and hazardous waste respectively. Moreover, the observation of the researcher asserts as the three color bins are available in the hospital where only safety box are in use to collect needles and other sharp materials. According to WHO (2011) the unsafe disposal of health-care waste (for example, contaminated syringes and needles) poses public health risks. Contaminated needles and syringes represent a particular threat as the failure to dispose them safely may lead to dangerous recycling and repackaging which lead to unsafe reuse. For example, WHO estimation for contaminated injections with contaminated syringes in year 2000 indicated:

Twenty-one million hepatitis B virus (HBV) infections (32\% of all new infections); two million hepatitis $\mathrm{C}$ virus (HCV) infections (40\% of all new infections); and at least 260, $000 \mathrm{HIV}$ infections (5\% of all new infections).

As all the officers of sample hospital responded that special attention is given to the needles and sharp materials when it is segregated, collected and disposed. Therefore, all the hospitals use yellow safety box and it is collected from each ward when $3 / 4$ of the space is full. The observation that is made in all hospital also confirms this practice. This implies that these sample hospitals are contributing their part by reducing the health risk that come due to the sharp materials.

Nevertheless, sharp materials are the most risk for health, there are others that have high risk for health and need special attention that the officials list. In Zewditu Hospital, even though it is known that waste should be segregated in different categories at the source in respect to the color code to avoid infection, this is not practiced. According to the official of the hospital, there was no a responsible department for more than a year that can take the responsibility and follow the activity of the health worker and cleaner to handle the waste properly from source to the final disposal. However, before a month the department of Hygiene and Environmental Health is established to handle this problem.

The hospitals have also been asked about the available facilities to manage the hazardous waste. All hospitals have incineration and Burial whereas $75 \%$ of the hospitals have the facilities of segregation and autoclave in the HCFs. In all segregation of waste in different category is done except in Zeweditu hospital where needle is the only infectious waste that segregation is only made. Segregation of waste at the source is done by nursing assistant for $50 \%$ of the hospitals and $50 \%$ of the hospital responded that healthcare providers can do it (Table2).

Table 4 Facilities for hazardous waste management

\begin{tabular}{llll}
\hline No. & Facilities & Frequency & Percent $(\%)$ \\
\hline 1 & Segregation & 3 & 75 \\
2 & Incineration & 4 & 100 \\
3 & AutoClave & 3 & 75 \\
4 & Burial & 4 & 100 \\
\hline
\end{tabular}

In all hospitals infectious and garbage bin is collected each day whereas safety box is collected when $3 / 4$ full. This waste is transported to incineration and burial sites by cleaners. Then the waste is placed according to the type. For instance, as it is observed in Gandi Memorial hospital gloves are soaked by chlorine solution chemicals to decontaminate the waste then it is collected with the general waste.

The Environmental Health Officials are asked about the employee education in relation to waste management. Except Zewditu Hospital, the rest have undergone training programme on hospital waste management and annual education on it for employee. In all hospitals the Environmental Health officers are interested to attend program on hospital waste management. From this it is possible to conclude that except for zewditu hospital, in the rest negligence/carelessness/ of the health worker and scarcity of budget can be a problem for improper segregations, collection and disposal of waste.

Generally, in all hospitals waste is collected to clean the ward as well as the compound to 
protect the workers, surrounding community and the environment but in a few hospital waste is collected only to clean the ward. This kind of hospital has the high probability of affect the health worker, cleaner, the surrounding community and the environment. For instance, it is observed in Zewditu hospital where no proper segregation of waste is made except the needle which is placed in yellow/white safety box and incinerated separately. To reduce this risk training is very essential.

\section{Disposal Mechanisms}

In the three hospitals (Black Lion, ALERT Centre and Gandi Memorandum Hospital), when bins are full, it is collected from each ward by the cleaner in accordance to the color. Then the cleaners dispose the non hazardous into garbage bin, the infectious waste and the needle is burned in the in different incinerator. The placenta and fetus are buried in the placenta pit (Figure1).

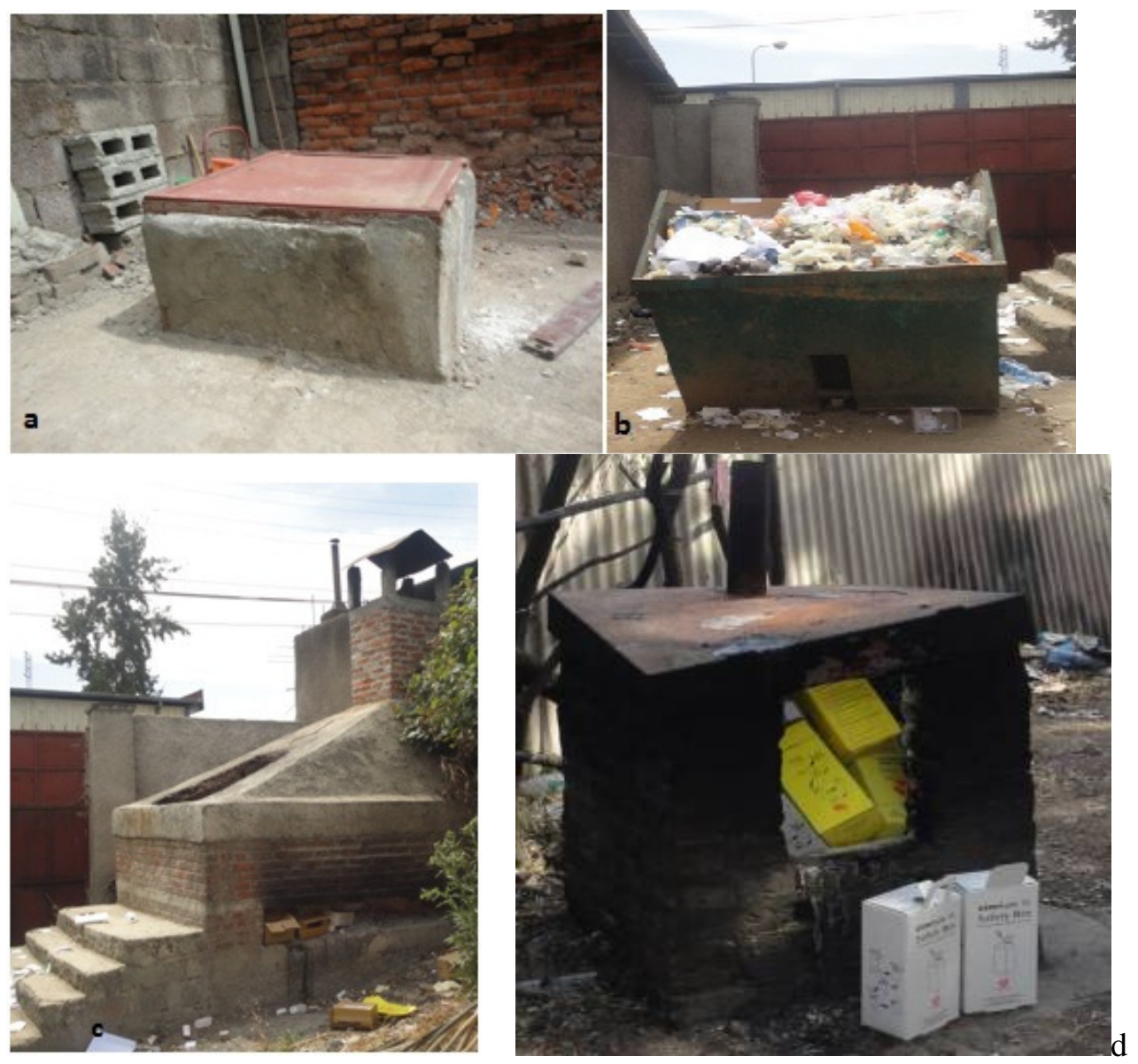

Figure 2 shows the waste disposal system of hospitals (a) placenta pit (b) garbage bin for general waste (c) incinerator for infectious waste and (d) incinerator for needle

After incineration the ash is buried and the general waste is collected by the City Cleaning Agency when garbage bin is full for the final disposal of general waste. Except Zewditu hospital, the rest use fenced place for the three waste disposal systems. In Zewditu hospital except the placenta pit which is far from the contact of the people, the needle and the other waste collected into the incinerators that are very much exposed to the society. According to WHO (2011) incorrect disposal of healthcare waste create other health risk. Therefore, the collected waste has to be disposed in a proper manner and the area has to be fenced to avoid the contact with the external community and reduce the threat of the HCFs waste.

\section{Challenges of Hazardous Waste Management by Healthcare Institutions}

Hygiene and Environmental Health officers of each hospital have been asked about the challenges they have faced in managing hazardous waste in their institutions. They responded that low awareness and negligence/carelessness of the health workers and cleaners are the main challenges. Lack of human resource is also another problem for ALERT Center and Zewditu Hospital. Besides, space is a problem for ALERT Center and Gandi Memorial Hospital for better 
management of the wastes. In Black Lion Hospital budget is a challenge.

In addition, Zewditu Hospital incinerator is not working properly but it is used for incineration and also not fenced separately to do so budget, space and human resource becomes a challenge (Figure2). Health workers do not use the color coded bin systems. As the researcher observed in Zewditu Hospital the three bin systems are available but only yellow/white safety box is used to segregate the needle from other waste. It is also observed only incinerator and placenta pit are available for waste disposal; there is no garbage for general waste in the compound. This implies whether the healthcare provider use the yellow and the black bin to segregate the infectious and the general waste respectively, the waste is disposed in the incinerator. Therefore, they may be forced to place both waste types in the same bin.

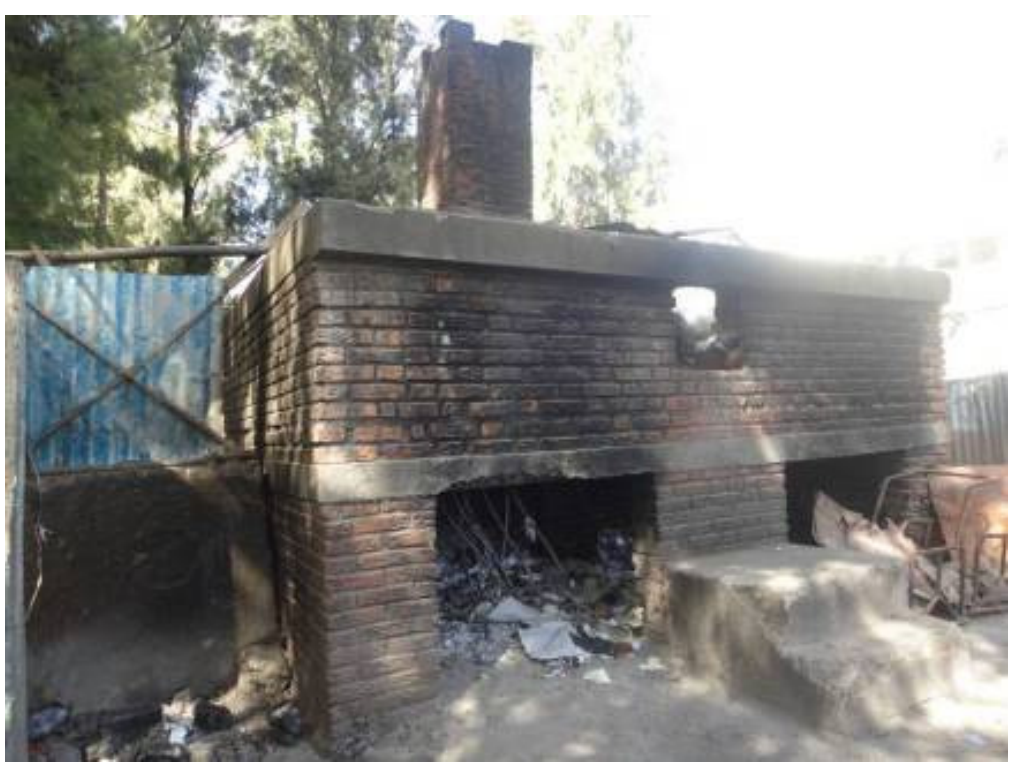

Figure 3: Zewditu hospital Incinerator (January, 2013)

In conclusion, Waste must be properly handled within the healthcare setting, even before it is taken for incineration, burial or other disposal, to protect clients, staff, and the community from the health risk due this waste (FMoH, 2004). The management of healthcare waste requires increased attention and diligence to avoid substantial disease burden associated with poor practice, including exposure to infectious agents and toxic substances. Incinerators provide a short-term solution especially for developing countries where options for waste disposal such as autoclave, shredder or microwave are limited (WHO, 2011). So hazardous and non-hazardous wastes should be separated at source, to reduce the volume of hazardous waste and minimize the cost to the institution for more expensive procedures required for managing and disposing of hazardous waste properly.

$$
\text { Suggestions from Hygiene and }
$$

Environmental Health Department for Hazardous Waste Management

Hygiene and Environmental Health Department of the Hospitals give suggestion for best management of waste for their institution.
In ALERT Centre it is suggested that "awareness and training program for all staff members, clear individual and group responsibility, monitoring procedures should be established at each level and resource should be allocated at all level." In Gandi memorandum Hospital awareness for staff is suggested. From Zewditu Hospital "build new incinerator, training for all staff about hazardous waste, and healthcare providers has to put each waste in line with the color coded bin" are suggested. Furthermore, from Black Lion Hospital "Training for worker and enough budgets should be allocated to manage the waste" are suggested. Form this it is possible to conclude that almost all institution suggested that awareness and training for staff are very essential. Furthermore, it is understood that each healthcare institution requires different things to manage wastes, this is because health institution can vary by the type of service they provide and the type of waste they generate can vary.

Practical Implementations of Laws and Regulation by Healthcare Institution in Addis Ababa National legislation is the basis for 
improving healthcare waste practices in any country. It establishes legal controls and consents the national agency responsible for the disposal of healthcare waste, usually the ministry of health, to apply pressure for their implementation. The national and the regional environmental protection agency may also be involved; there should be a clear designation of responsibilities before the law is approved (WHO, 1999). According to FDRE constitution (1991, Art 44) "all persons have the right to a clean and healthy environment" and Art 92 of the constitution states the environmental objectives. Both articles of the constitution designate as the people have the right to live in clean environment and to protect the environment. Based on this constitution EPA has produced different proclamations of this Proclamation no.300/2002 has the definition of hazardous waste. Moreover, Ethiopia ratifies Bamako convention and Basal convention amendment on proclamation no.356/2003 and 355/2003 respectively (Federal Negarit Gazeta, 2003). Addis Ababa City Government Regulation Number 24/2009, "it is appropriate to manage, collect and avoid west generated daily from different source of the city of Addis Ababa in manner that does not pollute the environment and harm the health of the society" (Addis Negari Gazeta,2009). Though the healthcare institutions understudy is not aware of the legislative act in relation to the waste, all of them collect, transport, and dispose the wastes that are generated during the healthcare services.

The regulation no.24/2009 also define the hazardous waste means "explosive flammable and toxic substance, radioactive materials, and various chemical those lists is indicated in the directive issued or be issued through time by agency, generated from different manufacturing organization health institutions and laboratories that cause harm to human and animal health or to the worse of the environment". According to the standard $15 \%$ of hospital waste is hazardous, therefore, in some hospitals they are managing in a way not to harm human, animal and the environment. For instance, regulation number 13/2004, Article 3 sub article 4 states that "... it is found necessary to sort wastes by type as compostable, non-compostable, reusable, non-servable, special and hazardous, and store them, in accordance with the directive issued by the Agency"(Addis Negari Gazeta,2004). Bur there are hospitals like Zewditu that failed to implement the regulation.
In 2004 FMoH prepared Infection Prevention Guidelines for Health care facilities in Ethiopia, this guidelines use in all types of medical and healthcare facilities-from large urban hospitals to small rural clinics. It is replaced by Infection Prevention and Patient Safety Reference Manual 2012 but still it is used by some hospital as guidelines $(\mathrm{FMoH}$, 2012). The infection Prevention Guidelines is known by all the sample hospitals except Zewditu hospital where this is guideline is not well known.

The Healthcare Waste Management National Guidelines (FMoH, 2008) is known and in use in ALERT Centre and Black Lion but not known by Gandi Memorial and Zewditu Hospitals. This indicates that as there is a gap in information and awareness of guidelines and regulation between the regional hospitals (Zewditu and Gandi memorial) and the federal hospitals (Black Lion and ALERT Centre). FMHACA official agrees that in most healthcare institutions there is low awareness on how to manage their waste and implementing the guidelines and directives. The FMHACA is responsible for the federal and teaching hospitals in Addis Ababa to create awareness control the activities and recommend while for the region responsibility is given for Health Bureaus. In Addis Ababa city administration health bureau has made inspection every time by preparing inspection checklist. According to Environmental Health Official, checklist is prepared on the basis of experience and educational background that can be modified every time.

Furthermore, FMHACA inspection and surveillance officer explained that lack of awareness about guidelines and the proclamations are challenges for the office to implement and act in accordance to it. By proclamation no.661/2009 FMHACA of Ethiopia has been given for control activity related to food, medicine and healthcare (Federal Negarit Gazeta, 2010). Therefore, in August 2011, the Authority prepared directive for Medicine Waste Management and Disposal Directives and they distributed the directive to all healthcare institution whereas for healthcare waste management the authority is preparing directive. It is also explained regions are having their own Food, Medicine and Health Care Administration and control. For instance Addis Ababa City Health Bureau is on the way to establish the authority and proclamation number 30/2012 is proclamation to establish Addis Ababa city government Food, Medicine 
and Healthcare Administration and Control Authority (Addis Negari Gazeta, 2012). This can help the region to work more on the management of waste like the federal one.

Finally, the officials at the regional and federal level have been asked whether they have an experience of taking legal action for those healthcare institutions that do not manage the waste properly. Both responded there is no healthcare institution that legal action is taken for improper management of the waste rather comment is given for those institutions that do not manage in accordance. Then follow up is done until they improve the activity on the basis of the comment given.

Generally, there is an urgent need to increase awareness about rules, regulations and procedures regarding this vital issue. Updated guidelines have to be distributed and checked the availability by designing strategy either at Federal or Regional level. There is no direct laws and regulation that separately state about the healthcare waste management but it is included in other waste management. Therefore, every healthcare facility providers has to a ware and act according to the guidelines.

\section{Conclusion}

It is clear that healthcare institution generate the waste that can affect the health of human, animals and the physical Environment. This is worse when the hazardous and the nonhazardous wastes are disposed together without segregation. The study was done on four hospitals of Addis Ababa about the hazardous waste management and implementation of laws ad regulation. From the study it is possible to conclude the wastes that are generated from the institution managed differently. Moreover, healthcare institutions do not have separate laws and regulation that can enforce them to properly manage the hazardous. However, there is guideline that the $\mathrm{MoH}$ has prepared that does not get proper follow up on how to implement it. Therefore, lack of awareness, scarcity of budgets, carelessness, lack of separate laws/regulation on healthcare waste and lack of human resources have been identified major challenges for improper managing of hazardous waste of healthcare facilities in Addis Ababa.

\section{Acknowledgement}

I am very much indebted to my instructor Ato Mekete Bekele for his invaluable comments and suggestions.

\section{References}

AAEPA, (2011). Quantification and characterization of Hazardous Waste in Addis Ababa. First Draft.

Abah , S.O. and Ohimain, E.I. (2011). Healthcare Waste Management in Nigeria: A Case Study. Journal of Public Health and Epidemiology, 3(3): 99-110.

Addis Ababa City Administration Health Bureau Report (2012). Addis Ababa, Ethiopia.

Addis Negari Gazeta (2004). Regulation number 13/2004, Waste Management, Collection and Disposal Regulation of Addis Ababa City Government. Addis Negari Gazeta of the City Government of Addis Ababa.

Addis Negari Gazeta (2009). Regulation number 24/2009, To Determine and Collect the Sanitary Service Tariff of the Addis Ababa City Government.

Addis Negari Gazeta (2012). Proclamation number 30/2012, A proclamation to establish Addis Ababa City Food, Medicine and Health care administration and control Authority.

Federal Government of Ethiopia (1995). Constitution of the Federal Democratic Republic of Ethiopia.

Federal Negarit Gazeta (2000). Proclamation number 192/2000, The Basel Convention on The Control of the Transboundary Movements of Hazardous Wastes and Their Disposal.

Federal Negarit Gazeta (2002). Proclamation number 300/2002, Environnemental Pollution Control Proclamation.

Federal Negarit Gazeta (2002). Proclamation number 279/2002, The Stockholm Convention on Persistent Organic Pollution Ratification Proclamation.

Federal Negarit Gazeta (2003). Proclamation number 356/2003, The Basal Convention Amendment Ratification Proclamation.

Federal Negarit Gazeta (2003). Proclamation number 355/2003, The Bamako Convention Ratification Proclamation.

Federal Negarit Gazeta (2010). Proclamation number 661/2009. A Proclamation to Provide for Food, Medicine and Health care administration and control.

FMoH (2004). Infection Prevention Guidelines for Healthcare Facilities in Ethiopia. Prepared by FMoH, Disease Prevention and Control Department Addis Ababa, Ethiopia 
FMoH (2008). Health Care Waste Management - National Guidelines. Addis Ababa, Ethiopia.

FMoH (2012). National Healthcare Waste Management Strategy and Implementation Plan 2012-2015, January, 2012-Ethiopia

FMoH (2012). Infection Prevention and Patient Safety. Reference Manual for Service Providers and Managers in Healthcare Facilities of Ethiopia, Second Edition February, 2012 Food, Medicine and Health Care Administration and Control Authority (FMHACA), 2011. Medicines Waste Management and Disposal Directive FMHACA, Addis Ababa, Ethiopia

Gabela, D.S. (2007). Health care waste management in public clinics in the iLembe District: a Situational Analysis. Published by Health Systems Trust, South Africa, November 2007

Indonesian-Swiss Country-Led Initiative (CLI), (2010). To Improve the Effectiveness of the Basel Convention Second Meeting. Wildhaus, Swizerland, 12-15 January 2010

Emmanuel, J. (2007). Best Environmental Practices and Alternative Technologies for Medical Waste Management. Eighth International Waste Management Ongress and Exhibition Institute of Waste Management of Southern AfricaBotswana Chapter 25TH to 28TH June 2007 Kasane, Botswana

Khajuria and A. Kumar (2007). Assessment of Healthcare Waste Generated by Government Hospital in Agra City, India

Muluken Azage and Abera Kumie (2010). Healthcare waste generation and its management system: the case of health centers in West Gojjam Zone, Amhara
Region, Ethiopia. Ethiopian Journal of Health Development, 24(2):119-126

Ogbonna, D. N., Chindah, A. and Ndubuisi, (2012). Waste Management Options for healthcare wastes in Nigeria: Case study of Port Harcort hospital. Journal of Public Health and Epidemology, 4(6): 156-169

Patwary, M. A. , Hare, W.T. Elahi, M.K., Hossain, S.S. and Sarker, M. (2009). Quantitative assessment of medical waste generation in the capital city of Bangladesh Waste Management, 29(8): 2392-2397.

Umar, A. and Yaro, A. (2009). Hospital Waste Management in Katsina State. Bajopas Journal of Pure Applied Science, 2(2): 22-26

Umar A., Yaro, A., and Abdukarim, B. (2009). Assessment of Healthcare Waste Management by some Selected Public Hospitals in Katsina State, Nigeria. Bajopas Journal of Pure Applied Science, 2(2): 13-15

WHO (1999). Safe Management of Waste from Heath-care Activities. WHO, Geneva. WHO Library Cataloguing-inPublication Data

WHO (2004). Safe Healthcare Waste Management. Policy Paper, Department of Protection of the Human Environment Water, Sanitation and Health. Geneva, Switzerland.

WHO (2011). Health-care waste management Fact sheet $\mathrm{N}^{\circ} 281$ http://www.who.int/mediacentre/factsheet s/fs253/en/index.html

WHO (2004). Preparation of national healthcare waste management plans in sub-Saharan countries, a guidance manual Geneva:

http://whqlibdoc.who.int/publications/200 5/9241546 62X.pdf 